\title{
Are We Asking All the Right Questions About Quality of Care in Low- and Middle-Income Countries?
}

\author{
Stephanie M. Topp ${ }^{1,2^{*}}$, Kabir Sheikh ${ }^{3,2}$
}

conceptualised as a spectrum than a dichotomy. ${ }^{8-10}$ What does bear more detailed investigation is the nature of these overlaps, and their influence on the experiences of service users. For instance, we do not know well enough (from LMIC contexts) what the impact is of introducing different market models - partnerships and incentives - on the quality of public sector services. Or of how variable state capacity to regulate and purchase services strategically influences the quality of private healthcare.

Look Beyond Health Worker Performance - Structural Factors Determine QoC

A distinct, but related trend in the literature is frequent conflation of the concepts of $\mathrm{QoC}$, and health worker performance. ${ }^{11}$ To be sure, users most often experience the health system through health workers, and as such, health worker performance both in relation to technical capability and person-centeredness are critical. Yet health worker performance is only one component of QoC. Conflation of the two concepts tends to (unfairly) place implicit responsibility for QoC on frontline health workers in LMICs. The conflation of quality and performance also diverts attention from equally important and pervasive structural influences on QoC such as market and governance failures, ' 'practical norms' that apply across the system, ${ }^{12}$ and workplace and patient provider trust and respect..$^{13-15}$ In doing so, it can promote short sighted policies that target health workers alone (eg, stand-alone performance based financing or training interventions) while reforms targeting broader structural determinants of those problems are overlooked.

Ask How QoC Can Be Improved, and Who Can Improve it? Considering that healthcare is provided in such varied social and organizational contexts, there is currently a bias towards standardisation and international comparability in global research on QoC, putatively addressed to a global audience of decision makers ${ }^{16,17}$ Research on QoC is likely to be more effective if it explicitly considers how it will lead to improvements in context, and engages the full range of people and institutions capable of bring about the desired improvements. A broader palette of methodological approaches than is currently in use is thus warranted, to respond to complex and varied health system contexts. Qualitative social science and "embedded" approaches in implementation science can help understand the social, organizational and relational determinants of $\mathrm{QoC}$, and need 
to be applied to complement the more quantitative forms of enquiry and evaluation that are currently privileged. ${ }^{4}$ Global research on QoC has made strides in embracing the perspectives of service users. ${ }^{18,19}$ However it also needs to include decision-makers at national and sub-national levels planners, regulators, managers and healthcare providers - as co-producers of research and directly address their knowledge needs. Those closer to the desired changes are best equipped to make them happen.

\section{Ethical issues}

Not applicable.

\section{Competing interests}

Authors declare that they have no competing interests.

\section{Authors' contributions}

Both authors conceived of the article. ST wrote the first draft. Both authors shared equally in the editing and refining of the manuscript.

\section{Authors' affiliations}

${ }^{1}$ College of Public Health, Medical and Veterinary Sciences, James Cook University, Townsville, QLD, Australia. ${ }^{2}$ Public Health Foundation of India, New Delhi, India. ${ }^{3}$ Nossal Institute for Global Health, University of Melbourne, Melbourne, VIC, Australia.

\section{References}

1. Kruk ME, Kelley E, Syed SB, Tarp F, Addison T, Akachi Y. Measuring quality of health-care services: what is known and where are the gaps? Bull World Health Organ. 2017;95(6):389-389A. doi:10.2471/ BLT.17.195099

2. Spurring Improvements in Primary Health Care. PHCPI website. https://phcperformanceinitiative.org/. Published 2017.

3. Quality of Care Network. A Network for Improving Quality of Care for Maternal, Newborn and Child Health. http://www.who.int/maternal_ child_adolescent/topics/quality-of-care/quality-of-care-brief-qed. pdf. Published 2017.

4. Hanefeld J, Powell-Jackson T, Balabanova D. Understanding and measuring quality of care: dealing with complexity. Bull World Health Organ. 2017;95(5):368-374. doi:10.2471/BLT.16.179309

5. Topp SM. The Lancet Global Health Commission on High Quality Health Systems-where's the complexity? Lancet Glob Health. 2017;5(6):e571. doi:10.1016/S2214-109X(17)30176-6

6. Coarasa J, Das J, Gummerson E, Bitton A. A systematic tale of two differing reviews: evaluating the evidence on public and private sector quality of primary care in low and middle income countries. Global Health. 2017;13(1):24. doi:10.1186/s12992-017-0246-4
7. Das J. A Letter to Oxfam: Reframing the questions around private sector health care. https://www.brookings.edu/blog/ future-development/2017/06/07/a-letter-to-oxfam-reframing-thequestions-around-private-sector-health-care/. Published June 7, 2017.

8. Sheikh K, Josyula LK, Zhang X, Bigdeli M, Ahmed SM. Governing the mixed health workforce: learning from Asian experiences. BMJ Glob Health. 2017;2(2):e000267. doi:10.1136/bmjgh-2016-000267

9. Sheikh K, Saligram PS, Hort K. What explains regulatory failure? Analysing the architecture of health care regulation in two Indian states. Health Policy Plan. 2015;30(1):39-55. doi:10.1093/heapol/ czt095

10. Morgan R, Ensor T, Waters H. Performance of private sector health care: implications for universal health coverage. Lancet. 2016;388(10044):606-612. doi:10.1016/S0140-6736(16)00343-3

11. Topp SM. Health worker performance, practice and improvement. In: George A, Scott K, Govender V, eds. A Health Policy and Systems Reader on Human Resources for Health. Geneva: World Health Organisation; 2017:73-88.

12. de Herdt T, Olivier de Sardin J-P. Real Governance and Practical Norms in Sub-Saharan Africa: The Game of the Rules. London and New York: Routledge; 2015.

13. Freedman LP, Kruk ME. Disrespect and abuse of women in childbirth: challenging the global quality and accountability agendas. Lancet. 2014;384(9948):e42-44. doi:10.1016/S0140-6736(14)60859-X

14. Gilson L, Palmer N, Schneider H. Trust and health worker performance: exploring a conceptual framework using South African evidence. Soc Sci Med. 2005;61(7):1418-1429. doi:10.1016/j. socscimed.2004.11.062

15. Topp SM, Chipukuma JM, Hanefeld J. Understanding the dynamic interactions driving Zambian health centre performance: a casebased health systems analysis. Health Policy Plan. 2015;30(4):485499. doi:10.1093/heapol/czu029

16. Spangler SA. Assessing skilled birth attendants and emergency obstetric care in rural Tanzania: the inadequacy of using global standards and indicators to measure local realities. Reprod Health Matters. 2012;20(39):133-141. doi:10.1016/S0968-8080(12)396034

17. Storeng KT, Behague DP. "Guilty until proven innocent": the contested use of maternal mortality indicators in global health. Crit Public Health. 2017;27(2):163-176. doi:10.1080/09581596.2016.12 59459

18. Ebrahimipour H, Vafaei Najjar A, Khani Jahani A, et al. Health system responsiveness: a case study of general hospitals in iran. Int $J$ Health Policy Manag. 2013;1(1):85-90. doi:10.15171/ijhpm.2013.13

19. Peltzer K. Patient experiences and health system responsiveness in South Africa. BMC Health Serv Res. 2009;9:117. doi:10.1186/14726963-9-117 